Article

\title{
Improving GLONASS Precise Orbit Determination through Data Connection
}

\author{
Yang Liu ${ }^{1,2}$, Maorong Ge ${ }^{2}$, Chuang Shi ${ }^{1}$, Yidong Lou ${ }^{1, *}$, Jens Wickert ${ }^{2}$ and Harald Schuh ${ }^{2}$ \\ Received: 28 September 2015; Accepted: 27 November 2015; Published: 2 December 2015 \\ Academic Editor: Vittorio M. N. Passaro \\ 1 GNSS Research Center, Wuhan University, 129 Luoyu Road, Wuhan 430079, China; \\ liudaweng@126.com (Y.L.); shi@whu.edu.cn (C.S.) \\ 2 German Research Center for Geosciences (GFZ), Telegrafenberg, Potsdam 14473, Germany; \\ maor@gfz-potsdam.de (M.G.); wickert@gfz-potsdam.de (J.W.); schuh@gfz-potsdam.de (H.S.) \\ * Correspondence: ydlou@whu.edu.cn; Tel.: +86-27-6877-8595; Fax: +86-27-6877-8890
}

\begin{abstract}
In order to improve the precision of GLONASS orbits, this paper presents a method to connect the data segments of a single station-satellite pair to increase the observation continuity and, consequently, the strength of the precise orbit determination (POD) solution. In this method, for each GLONASS station-satellite pair, the wide-lane ambiguities derived from the Melbourne-Wübbena combination are statistically tested and corrected for phase integer offsets and then the same is carried out for the narrow-lane ambiguities calculated from the POD solution. An experimental validation was carried out using one-month GNSS data of a global network with 175 IGS stations. The result shows that, on average, $27.1 \%$ of the GLONASS station-satellite pairs with multiple data segments could be connected to a single long observation arc and, thus, only one ambiguity parameter was estimated. Using the connected data, the GLONASS orbit overlapping RMS at the day boundaries could be reduced by $19.2 \%$ in ideal cases with an averaged reduction of about $6.3 \%$.
\end{abstract}

Keywords: GLONASS; data connection; precise orbit determination; orbit precision

\section{Introduction}

GLONASS is currently another Global Navigation Satellite System (GNSS) with full operational capability other than GPS. The precise orbit determination (POD) is the prerequisite for numerous GNSS applications with the demand of high accuracy. Since 1998, the GLONASS precise orbit products were developed within the International GLONASS Experiment (IGEX) [1]. From 2001, the International GNSS Service (IGS) [2] established the International GLONASS Service Pilot Project (IGLOS-PP) [3]. Through these efforts POD of the GLONASS constellation has been gradually improved [4-7] and its orbit precision currently reaches the centimeter level. However, it is still markedly worse than that of GPS in terms of the orbit agreement among different IGS analysis centers and over-day boundaries [8-10]. One of the major reasons is that the GPS solution is very much strengthened by its successful ambiguity resolution even over baselines up to several thousand kilometers [11-14]. Unlike GPS, which adopts code division multiple access (CDMA), the present GLONASS uses frequency division multiple access (FDMA) to distinguish the signals from individual satellites [15]. It introduces different hardware biases to each receiving channel, thus makes its ambiguity resolution rather difficult, especially for long baselines.

In order to increase the strength of the GLONASS solution, several studies on the GLONASS ambiguity resolution have been carried out. Most of the developed mathematical and stochastical modeling methodologies and specific ambiguity resolution strategies are systematically summarized and investigated by Wang et al. [16]. It is well known that through the calibration of carrier-phase 
inter-frequency biases at the GLONASS receiver-end, the ambiguity resolution for baselines of several hundred kilometers can be achieved [17]. In the IGS data processing at CODE (Center for Orbit Determination in Europe), for baselines shorter than $200 \mathrm{~km}$, the GLONASS ambiguity resolution is enabled for all satellites, whereas for longer baselines only ambiguities of the same frequency channels are considered in order to improve the orbit quality [18]. However, most of the IGS analysis centers have not yet implemented the GLONASS ambiguity resolution most likely due to its complexity and limited benefit.

It is quite meaningful to further improve the accuracy of GLONASS orbit for high-precision GNSS applications. A novel method, i.e., data connection rather than ambiguity resolution, is introduced and investigated in this contribution. As demonstrated in [19], when using carrier ranges [20] generated with the undifferenced integer ambiguities in precise point positioning (PPP) $[21,22]$ for single stations, the data continuity for GPS satellites is increased and the averaged RMS of the overlapping orbits is reduced. It is also demonstrated that most observation segments, even that from separated satellite passes with a data gap of hours, can be connected. Inspired by this fact, we present a method for data connection to improve GLONASS orbit quality by using the connected data. Since currently the GLONASS PPP ambiguity resolution is rather difficult to be realized on a global scale, instead of using the carrier-range method, the data are connected by checking the consistency of the wide-lane and narrow-lane ambiguities of different observation segments. After the successful data connection, GLONASS orbit quality is expected to be improved. In this contribution, we try to make a thorough performance assessment of the data connection method and analyze possible benefits for GLONASS orbit determination.

The data connection method is presented in the next section. Then experimental validation is described with the details of the network, data set and processing strategy. The performance of the data connection and the improvement on GLONASS orbits in terms of overlapping RMS are presented and investigated in subsequent sections, followed by conclusions and suggestions.

\section{Data Connection Method}

In general, we assume that undifferenced ionosphere-free phase $\left(L_{c}\right)$ and range $\left(P_{c}\right)$ observations are used in the data processing, and the observation equations are:

$$
\begin{aligned}
& L_{c}=\frac{f_{1}^{2}}{f_{1}^{2}-f_{2}^{2}} L_{1}-\frac{f_{2}^{2}}{f_{1}^{2}-f_{2}^{2}} L_{2}=\rho+d t_{R}^{S}+\lambda_{1} b_{c} \\
& P_{c}=\frac{f_{1}^{2}}{f_{1}^{2}-f_{2}^{2}} P_{1}-\frac{f_{2}^{2}}{f_{1}^{2}-f_{2}^{2}} P_{2}=\rho+d t_{R}^{S}
\end{aligned}
$$

where $L_{1}, L_{2}, P_{1}$, and $P_{2}$ are phase and range observations of the two frequencies $f_{1}$ and $f_{2}$ in the unit of length, respectively. $d t_{R}^{S}$ is the receiver clock bias minus satellite clock bias. $\rho$ is the non-dispersive delay including the geometric distance, the tropospheric delay, and any other delay which affects the observations identically, with the correction of the phase center [23], the phase windup effect [24], and the satellite-dependent differential code biases (DCB) [25]. $b_{\mathcal{c}}$ is the $L_{\mathcal{c}}$ ambiguity. Multipath effect, hardware delay, and noise are not included in the equation for clarity.

For the ambiguity resolution, ambiguity $b_{c}$ is usually expressed by wide-lane (WL) and narrow-lane (NL) ambiguities [12] as:

$$
b_{c}=\frac{f_{1} f_{2}}{f_{1}^{2}-f_{2}^{2}} b_{w}+\frac{f_{1}}{f_{1}+f_{2}} b_{n}
$$

Usually, WL ambiguities are fixed based on the Melbourne-Wübbena (MW) combination [26,27], whereas NL ambiguities are derived based on the fixed $W L$ and the estimated ionosphere-free ambiguities and fixed accordingly. 
We follow the procedure of the ambiguity resolution to connect the WL ambiguities first, and then the NL ambiguities. Without loss of generality, we assume that there are $n$ observation segments for a station-satellite pair and their WL ambiguities and the corresponding standard deviations computed using the MW combination are $\left[b_{w i}, \sigma_{w i}\right]_{i=1,2, \ldots, n}$. For the observation segments $j$ and $k$, we can get the difference and its standard deviation as:

$$
\begin{gathered}
b_{w j k}=b_{w j}-b_{w k} \\
\sigma_{w j k}=\sqrt{\sigma_{w j}^{2}+\sigma_{w k}^{2}}
\end{gathered}
$$

If there is a unique integer value $I_{w}$ and it satisfies:

$$
I_{w}-3 \sigma_{w j k}<b_{w j k}<I_{w}+3 \sigma_{w j k}
$$

then WL of the two segments can be connected by applying the phase integer offset of $I_{w}$. Obviously, the standard error of the difference, i.e., $\sigma_{w j k}$ must be small enough in order to obtain a unique phase integer offset.

A more sophisticated way to make the decision whether the two WL ambiguities can be connected is to use the following probability function [12]:

$$
\begin{gathered}
P=1-\sum_{n=1}^{\infty}\left[\operatorname{erfc}\left(\frac{n-\left(b_{w j k}-I\right)}{\sqrt{2} \sigma_{w j k}}\right)-\operatorname{erfc}\left(\frac{n+\left(b_{w j k}-I\right)}{\sqrt{2} \sigma_{w j k}}\right)\right] \\
\operatorname{erfc}(x)=\frac{2}{\sqrt{\pi}} \int_{x}^{\infty} e^{-t^{2}} d t
\end{gathered}
$$

where $I$ is the integer candidate for $b_{w j k}$ to be tested.

Taking the confidence level $\alpha$ of data connection as $0.1 \%$, if $P$ is bigger than $1-\alpha$, the WL ambiguities of the two segments can be connected confidently with the phase integer offset $I_{w}=I$, otherwise they cannot be connected.

After the WL ambiguities are connected with an phase integer offset $I_{w}$, i.e., $b_{w j}=b_{w k}+I_{w}$, we can get the corresponding NL ambiguity with the connected WL ambiguities and the ionosphere-free ambiguities estimated from the adjustment as:

$$
\begin{gathered}
b_{n k}=\frac{f_{1}+f_{2}}{f_{1}} b_{c k}-\frac{f_{2}}{f_{1}-f_{2}} b_{w k} \\
b_{n j}=\frac{f_{1}+f_{2}}{f_{1}} b_{c j}-\frac{f_{2}}{f_{1}-f_{2}}\left(b_{w k}+I_{w}\right)
\end{gathered}
$$

Similar to the wide-lane, their difference and the corresponding standard deviation are:

$$
\begin{aligned}
& b_{n j k}=b_{n j}-b_{n k} \\
& \sigma_{n j k}=\frac{f_{1}+f_{2}}{f_{2}} \sqrt{\sigma_{c j}^{2}+\sigma_{c k}^{2}-2 \sigma_{c j k}}
\end{aligned}
$$

It should be pointed out that the correlation term in Equation (9) could not be ignored, as the STD of the two undifferenced ambiguities from the adjustment are usually rather large. Moreover, for the sake of computational efficiency, the covariance of ambiguities is not available, in this case, a default value of 0.05 cycles can be applied at least for processing data of long segments from our expertise in the previous studies on ambiguity resolution [28] as well as in this research.

Similar to the WL connection, we can determine whether the two NL ambiguities can be connected according to the probability Equation (5). Based on the approximation, if the fractional parts of the two NL ambiguities are close to each other, with the difference of 0.15 cycles, the two NL 
ambiguities can be connected. Let the corresponding phase integer offset be $I_{n}$, we have $b_{n j}=b_{n k}+I_{n}$. It is worth mentioning that two observation segments of a station-satellite pair are regarded as connected, only when both the WL and NL ambiguities are connected.

By considering that $b_{w}=b_{1}-b_{2}$ and $b_{n}=b_{1}$, we can get the relationship between the L1 and L2 ambiguities of the two segments, respectively, as:

$$
\left\{\begin{array}{l}
b_{1 k}=b_{n k} \\
b_{2 k}=b_{n k}-b_{w k} \\
b_{1 j}=b_{n k}+I_{n} \\
b_{2 j}=b_{n k}-b_{w k}+\left(I_{n}-I_{w}\right)
\end{array}\right.
$$

This can also be expressed by the phase integer offsets between the observation segments $k$ and $j$ in the L1 and L2 frequencies as $N_{1}$ and $N_{2}$, with $N_{1}=I_{n}$, and $N_{2}=I_{n}-I_{w}$. Applying the phase integer offsets to the second segment, these two segments are connected and only the ambiguity at the data beginning is remaining.

Performing this data connection procedure for all the observation segments of a station-satellite pair iteratively until no new segments can be connected any more. After successful connection, the estimates of the connected segment can be updated for further processing. It should be mentioned that the data connection method can be applied to GLONASS FDMA signals, as well as to CDMA signals adopted by the other constellations, as the connection is carried out for each station-satellite pair.

As to the implementation issue, the phase observations are corrected with the determined phase integer offsets and for each station a new RINEX observation file is generated with a special flag indicating the corrected phase integer offsets. With such corrected observation files, the estimation processing is carried out in the same way as usual except that no ambiguity is estimated for the connected segments. In practice, careful screening of the post-fit residuals should be implemented to confirm the correctness of the connection and to remove possible incorrect connections.

\section{Experimental Validation}

In order to validate the connection method described above, an experiment was carried out for data connection in GLONASS POD. We adopted combined orbit determination of GPS and GLONASS on the observation level using globally well distributed IGS stations with daily observations, as the combination with GPS can improve the GLONASS satellite orbits [8]. Observations of 175 IGS stations from DOY 270 to 300, 2013 were used. Figure 1 shows the geographical distribution of the tracking stations, where 32 GPS-only stations are represented by red dots and the rest GPS/GLONASS stations by blue triangles.

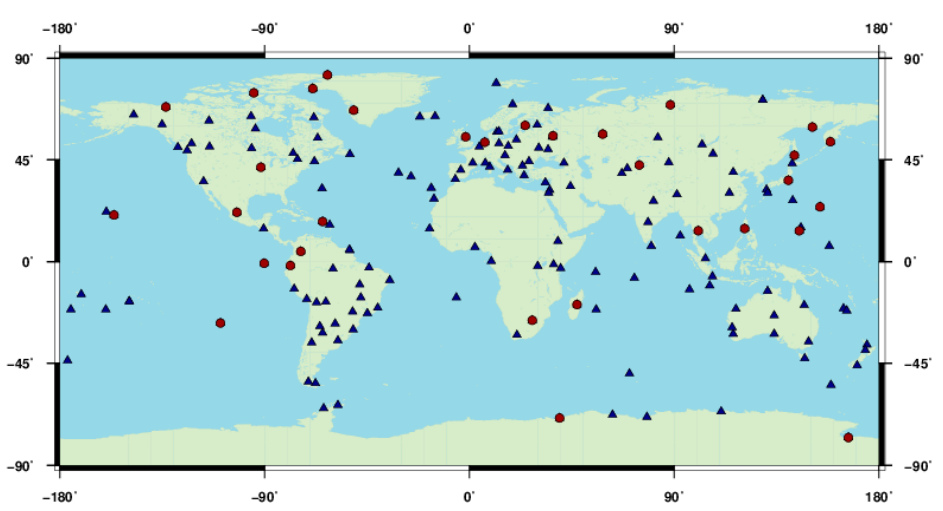

Figure 1. Geographical distribution of the 175 IGS tracking stations used in the experiment, dots are for GPS-only stations and triangles for GPS/GLONASS stations. 
The Positioning and Navigation Data Analyst (PANDA) [29,30] software was adapted and used for data connection and POD processing in this study. In the combined GPS/GLONASS processing, the inter-frequency bias (IFB) in a receiver was estimated as a constant for each GLONASS frequency. Observation segments shorter than 40 min were deleted. Ambiguity resolution for baselines shorter than $3500 \mathrm{~km}$ was carried out for GPS using the method in [14] whereas no ambiguity resolution for GLONASS. In the GLONASS data connection, no connection was undertaken if the distance between the ambiguity difference and its closest integer was larger than 0.15 cycles. The POD solution was carried out in accordance with the routine processing at the GFZ (German Research Center for Geosciences) IGS Analysis Center. The other important options of processing strategy about observation model and force model in the experiment are listed in Table 1.

Table 1. Observation and force models.

\begin{tabular}{|c|c|}
\hline Basic observable & Undifferenced ionosphere-free code and phase combination \\
\hline Sampling rate & $300 \mathrm{~s}$ \\
\hline Arc length & 1 day \\
\hline Cutoff elevation & $7^{\circ}$ \\
\hline Weighting & $\begin{array}{l}\text { Priori precision } 0.01 \text { cycle and } 0.6 \mathrm{~m} \text { for raw phase and code, } \\
\text { respectively Elevation-dependent, } 1 \text { for } \mathrm{E}>30^{\circ} \text {, otherwise } 2^{*} \sin (\mathrm{E})\end{array}$ \\
\hline Phase center correction & $\begin{array}{l}\text { PCO (Phase Center Offset) and PCV (Phase Center Variation) for GPS, } \\
\text { GLONASS satellites and stations, igs08.atx [23] }\end{array}$ \\
\hline Phase wind up & Corrected [24] \\
\hline Tropospheric delay & $\begin{array}{l}\text { GMF (Global Mapping Function) [31], priori delay [32], 2-hourly ZTD } \\
\text { (Zenith Tropospheric Delay), 24-hourly gradients [33] }\end{array}$ \\
\hline Clock error & White noise \\
\hline Earth Rotation Parameters & $\begin{array}{l}\text { IERS (International Earth Rotation and Reference Systems Service) } \\
\text { C04 [34] tight constraint }\end{array}$ \\
\hline Tide displacement & IERS Conventions 2010 [35], FES2004 [36] \\
\hline Relativity effect & IERS Conventions 2010 \\
\hline Earth gravity & EIGEN_GL04C [37] up to $12 \times 12$ \\
\hline N-body gravitation & $\begin{array}{l}\text { Sun, Moon, Mercury, Venus, Mars, Jupiter, Saturn, Uranus, Neptune, } \\
\text { Pluto regarded as point masses, JPL Planetary Ephemeris DE405 }\end{array}$ \\
\hline Solar radiation & $\begin{array}{l}\text { Reduced Empirical CODE Orbit Model (ECOM) five parameters } \\
\text { without a background model [38] }\end{array}$ \\
\hline Attitude model & GPS model [39], GLONASS model [40] \\
\hline Earth radiation and antenna thrust & Effects acting on the Box-Wing model applied [41] \\
\hline Additional empirical acceleration & $\begin{array}{l}\text { Constant and periodic once-per-revolution accelerations along-track } \\
\text { not estimated }\end{array}$ \\
\hline
\end{tabular}

We first analyzed the data connection effectiveness for all the stations, for different receiver types, and then for each GLONASS satellite. Afterwards, GLONASS orbits before and after the data connection were compared with the IGS final orbits. Then, the overlapping RMS of the solution on the day boundaries was assessed to confirm the possible improvements of GLONASS orbit quality.

\subsection{Data Connection Ratio}

To assess the effectiveness of the data connection, we define an empirical connection ratio, i.e., the number of GLONASS station-satellite pairs that are successfully connected to only one arc divided by the number of GLONASS station-satellite pairs that originally have various observation segments. In the validation experiment, typically a station could track all the 24 GLONASS satellites on a daily basis, where the majority GLONASS satellites had more than one observation segments. Taking the average for all the stations, there were 17 GLONASS satellites that had multiple observation segments in the daily observing duration. The number was reduced to 12.4 on average after the proposed data connection, i.e., 4.6 extra GLONASS satellites were connected to have only one observation arc. Specifically for the WL connection, there were 11.3 extra satellites that were connected to only one arc and the connection ratio was $66.5 \%$. For the NL connection, there were 4.6 extra satellites connected to 
only one arc and the connection ratio was $27.1 \%$. Obviously, the NL is more difficult to be connected because it has a much shorter wavelength of about $11 \mathrm{~cm}$ compared with the WL of about $84 \mathrm{~cm}$.

On average, there were about 44 ambiguity parameters per station before the data connection and the number was reduced to 39 after the data connection. For all the stations in the daily solution, the total number of GLONASS ambiguities was 6257 and it was reduced to 5546 after the data connection with a reduction percentage of $11.4 \%$.

The connection ratios of each different receiver type listed in Table 2 were calculated and are shown in Figure 2 for WL and NL ambiguities, respectively. Since the WL ambiguities are computed using the MW combination, it is only influenced by the measurement noises including carrier phase and code multipath. Therefore, the WL connection ratio among individual receiver types should be attributed mainly to the measurement quality of receiver types. For the NL connection ratio, there was almost no significant difference among individual receiver types, and the connection ratio was rather low of about $26.2 \%$. It is easy to understand that the NL connection is limited by the quality of the solution from which NL ambiguity is derived. This also means that the estimation of the ionosphere-free ambiguity must be further improved in order to obtain a better connection result.

Table 2. GLONASS tracking receiver types and numbers used in the experiment.

\begin{tabular}{cc}
\hline Manufacturer & Receiver Number \\
\hline JAVAD & 22 \\
JPS & 12 \\
LEICA & 43 \\
SEPT & 5 \\
TPS & 16 \\
TRIMBLE & 44 \\
\hline
\end{tabular}

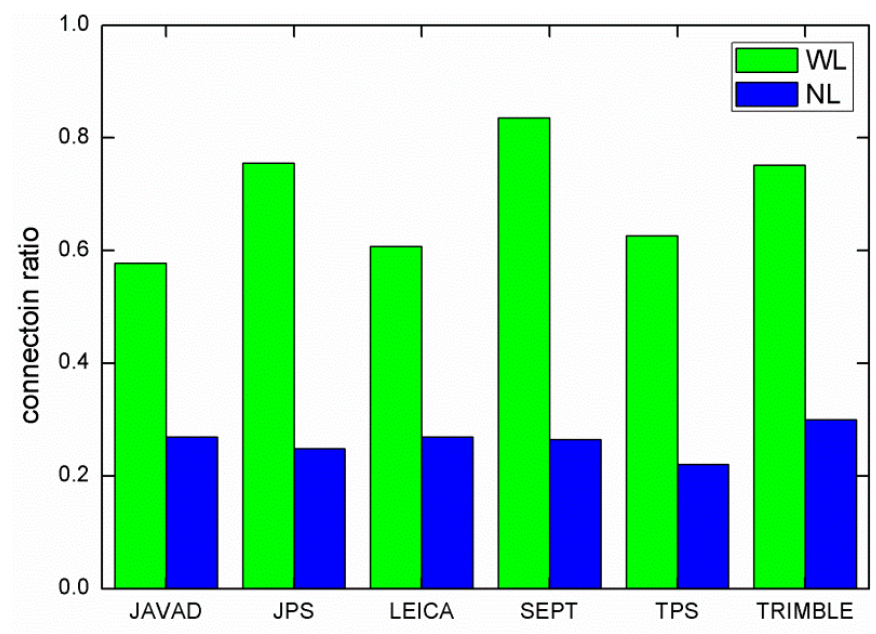

Figure 2. Wide-lane and narrow-lane connection ratio for different type of receivers.

The connection ratios for individual GLONASS satellites were also calculated and are shown in Figure 3 for WL and NL ambiguities, respectively. Slight differences can be found among individual GLONASS satellites, which are more pronounced for WL connection than for NL connection. For the WL connection, we attribute the differences to the measurement noises and the stability of individual satellite hardware delays, as no other factors seem plausible. For the NL connection, the differences are rather small and could be caused by the different tracking geometry and inaccurate modeling. It should be mentioned that the undifferenced ambiguities are affected by a combination of code and phase hardware delays in the satellite and the receiver [42]. The possible temporal changes in the satellite or the receiver hardware delays can be one error source affecting the success of the data 
connection method. For example, the long-term temporal variation in the receiver DCB is found to be linearly correlated with the ambient outdoor temperatures [43]. The impact on the daily orbit solutions may also affect the data connection ratio.

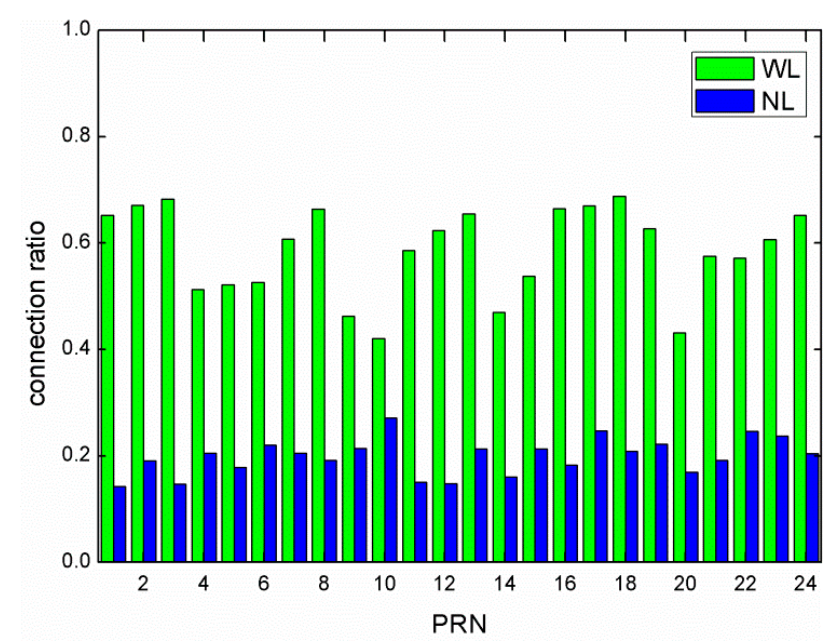

Figure 3. Wide-lane and narrow-lane connection ratio for individual GLONASS satellites.

\subsection{Improvement on GLONASS Satellite Orbits}

In order to show the influence of the data connection, the GLONASS satellite orbits are compared before and after the data connection. The individual GLONASS satellite orbit variation is computed every five minutes in each day and averaged in RMS during the experiment period. The result is shown in Figure 4. The orbit variation is $7.5 \mathrm{~mm}$ on average for all the GLONASS satellites. The magnitude of the orbit variation is considerable taking into account that the connection ratio is relatively low and the connection is carried out on a single station basis without strong constraints among different stations.

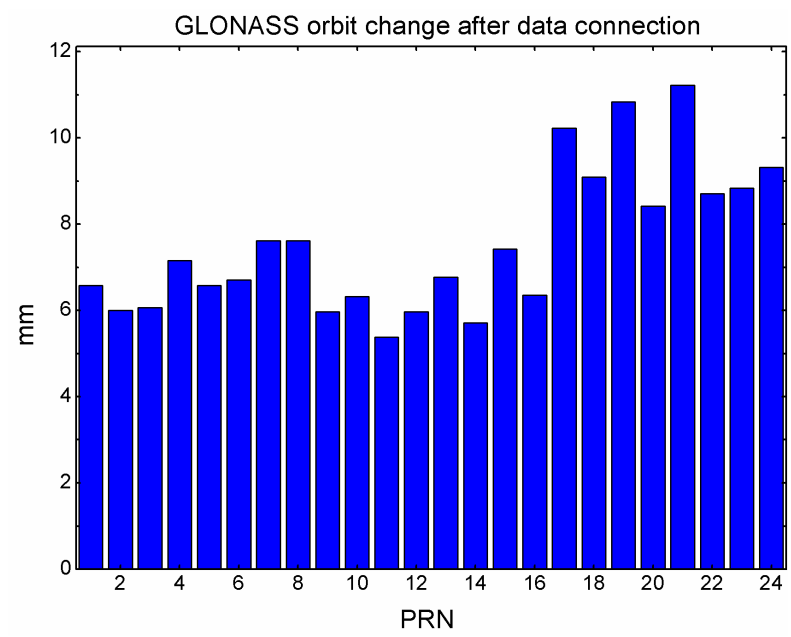

Figure 4. GLONASS satellite orbit variation after the data connection.

We first compared the GLONASS satellite orbits before and after the data connection with the IGS final GLONASS orbits. After a seven-parameter Helmert transformation for removing possible systematic differences, the median RMS during the experimental period is shown in Figure 5. The RMS of all the GLONASS satellites was almost the same of $23.7 \mathrm{~mm}$ for the two solutions. We can also see that for many GLONASS satellites, the RMS got slightly larger of about $1 \mathrm{~mm}$ after the data 
connection. There was no significant difference between the two solutions, i.e., the orbits were not dramatically improved by the data connection method from the point of orbit differences with IGS final products. It may indicate that it is difficult using the IGS final products to assess the possible orbit improvement of the data connection, although they are of high quality.

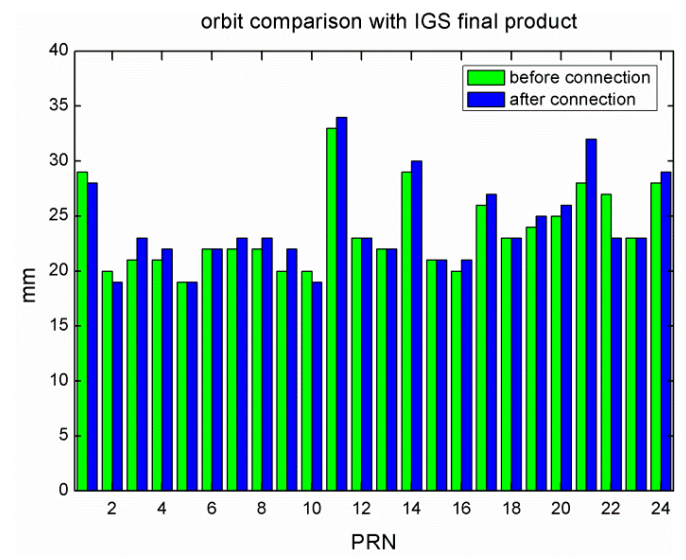

Figure 5. Comparison of GLONASS orbits before and after the data connection with IGS final products.

For more realistic orbit quality assessment, the discontinuity at the day boundary is adopted as a measure in Griffiths and Ray [9]. The overlapping orbit RMS of the GLONASS satellites before and after the data connection were calculated and plotted in Figure 6. Since the overlapping RMS involve orbits from two consecutive days, the inferred orbit precision for a single daily solution should be divided by $\sqrt{2}$.

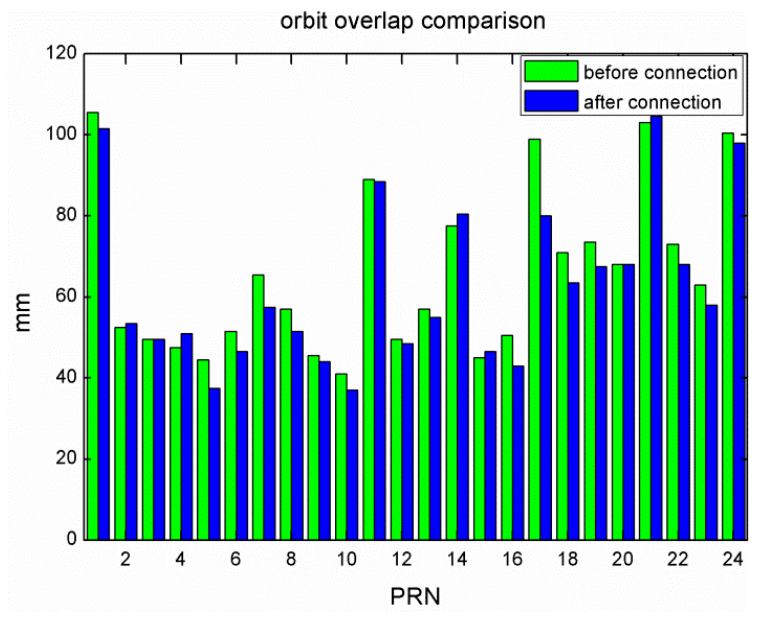

Figure 6. Overlapping orbit RMS for the solution before (green) and after data connection (blue).

Usually, the median RMS of all the satellites is selected as an indicator for the orbit quality because it can avoid the effect of bad satellites with very large RMS [8]. The median RMS before the data connection was $60.0 \mathrm{~mm}$ and it was reduced to $56.2 \mathrm{~mm}$ by the data connection. The overall improvement was about $6.3 \%$. For individual satellites, the largest improvement was by $19.2 \%$ while the smallest improvement was by $0.6 \%$. Thus, data connection can indeed increase the solution strength and improve the orbit quality, although the improvement is not as strong as that of ambiguity resolution which substantially improves the orbit quality for GPS satellites. For comparison, the overlapping orbit RMS of all the GPS satellites was improved by about $30.5 \%$ 
after ambiguity resolution for the experiment period. From Figure 6, five satellites show slight degradation rather than improvement. The possible correlations with the orbital plane, the satellite type, and launch time were checked but no obvious correlation was found, which should be further investigated. Nevertheless, data connection could improve the overall GLONASS orbit quality, before the GLONASS ambiguity resolution for long baselines up to several thousands of kilometers can be implemented reliably.

\section{Conclusions and Suggestions}

Since the reliable GLONASS ambiguity resolution over long baselines is not yet available, we developed a method for data connection to increase the strength of global network solutions. The WL ambiguities of all segments are derived from the MW combination and their NL are calculated based on the connected WL and the estimated ambiguities in the adjustment. The WL and NL ambiguities of each GLONASS station-satellite pair are statistically tested and corrected for phase integer offsets. In this way, GLONASS station-satellite pairs with multiple data segments can be connected and even to a single observation arc, i.e., only one ambiguity parameter is remaining. Since the number of ambiguities is reduced, the strength of the solution will be increased and consequently the orbit quality is improved with the connected data.

The connection method and its impact on satellite orbits were investigated through an experimental validation using a global network of IGS ground tracing stations. The effectiveness of the connection method was investigated for different receiver types and individual GLONASS satellites. The statistics show that on average $27.1 \%$ of the GLONASS station-satellite pairs with multiple data segments can be connected to a single observation arc. The major restriction is in the NL connection most likely due to inaccurate modeling in the estimation.

The RMS of overlapping orbits for the solutions with and without the data connection were computed and analyzed. The median RMS of the overlapping orbits for all the GLONASS satellites was reduced from $60.0 \mathrm{~mm}$ to $56.2 \mathrm{~mm}$ after the data connection, which corresponds to an averaged improvement of about $6.3 \%$ over all satellites. Furthermore, the largest improvement was up to $19.2 \%$ for a single satellite. As the GLONASS ambiguity resolution is not reliably available, the data connection provides an alternative way to improve the orbit quality, although it is not as significant as the ambiguity resolution for GPS.

Finally, from the results of one-month POD experiment, we could conclude that the quality of GLONASS satellites orbits could be slightly improved by the data connection method. The improvement could be increased by more accurate modeling in the adjustment, like the solar radiation pressure model. The recent developments of GLONASS orbit modeling, e.g., by improving the empirical ECOM model [44] or applying the adjustable box-wing model [45], should be implemented and investigated in the future. Furthermore, the connection can still be utilized to improve the solution even if the reliable GLONASS ambiguity resolution is implemented.

Acknowledgments: The first author is financially supported by the China Scholarship Council (CSC) for his study at the German Research Centre for Geosciences (GFZ). We thank the IGS for providing GNSS ground tracking data. This work is supported by the National Nature Science Foundation of China (No. 41374034) and the National “863 Program” of China (Grant No. 2014AA123101). The scholarship from Collaborative Innovation Center of Geospatial Technology of China is gratefully acknowledged.

Author Contributions: Liu, Ge, Shi and Lou provided the initial idea for this study. Liu adapted the software and carried out the data analysis. Liu and Ge wrote the main manuscript. Shi, Lou, Wickert and Schuh helped with the writing. All authors reviewed the manuscript.

Conflicts of Interest: The authors declare no conflict of interest.

\section{References}

1. Willis, P.; Beutler, G.; Gurtner, W.; Hein, G.; Neilan, R.E.; Noll, C.; Slater, J. IGEX: International GLONASS experiment-Scientific objectives and preparation. Adv. Space Res. 1999, 23, 659-663. [CrossRef] 
2. Dow, J.; Neilan, R.E.; Rizos, C. The International GNSS Service in a changing landscape of Global Navigation Satellite Systems. J. Geod. 2009, 83, 191-198. [CrossRef]

3. Slater, J.A.; Weber, R.; Fragner, D. The IGS GLONASS Pilot Project-Transitioning an experiment into an operational GNSS service. In Proceedings of the ION GNSS 2004, Long Beach, CA, USA, 21-24 September 2004; pp. 1749-1757.

4. Ineichen, D.; Springer, T.; Beutler, G. Combined processing of the IGS and the IGEX network. J. Geod. 2001, 75, 575-586. [CrossRef]

5. Kuang, D.; Bar-Sever, Y.E.; Bertiger, W.I.; Hurst, K.J.; Zumberge, J.F. GPS-assisted GLONASS orbit determination. J. Geod. 2001, 75, 569-574. [CrossRef]

6. Romero, I.; Garcia, C.; Kahle, R.; Dow, J.; Martin-Mur, T. Precise orbit determination of GLONASS satellites at the European space agency. Adv. Space Res. 2002, 30, 281-287. [CrossRef]

7. Weber, R.; Slater, J.A.; Fragner, E.; Glotov, V.; Habrich, H.; Romero, I.; Schaer, S. Precise GLONASS orbit determination within the IGS/IGLOS-Pilot Project. Adv. Space Res. 2005, 36, 369-375. [CrossRef]

8. Fritsche, M.; Sośnica, K.; Rodríguez-Solano, C.; Steigenberger, P.; Wang, K.; Dietrich, R.; Dach, R.; Hugentobler, U.; Rothacher, M. Homogeneous reprocessing of GPS, GLONASS and SLR observations. J. Geod. 2014, 88, 625-642. [CrossRef]

9. Griffiths, J.; Ray, J. On the precision and accuracy of IGS orbits. J. Geod. 2009, 83, 277-287. [CrossRef]

10. Li, X.; Ge, M.; Dai, X.; Ren, X.; Fritsche, M.; Wickert, J.; Schuh, H. Accuracy and reliability of multi-GNSS real-time precise positioning: GPS, GLONASS, BeiDou, and Galileo. J. Geod. 2015, 89, 607-635. [CrossRef]

11. Blewitt, G. Carrier Phase Ambiguity Resolution for the Global Positioning System Applied to Geodetic Baselines up to $2000 \mathrm{~km}$. J. Geophys. Res. 1989, 94, 10187-10203. [CrossRef]

12. Dong, D.; Bock, Y. Global Positioning System Network Analysis with Phase Ambiguity Resolution Applied to Crustal Deformation Studies in California. J. Geophys. Res. 1989, 94, 3949-3966. [CrossRef]

13. Mervart, L. Ambiguity Resolution Techniques in Geodetic and Geodynamic Applications of the Global Positioning System. Ph.D Thesis, University of Berne, Berne, Switzerland, 1995.

14. Ge, M.; Gendt, G.; Dick, G.; Zhang, F.P. Improving carrier-phase ambiguity resolution in global GPS network solutions. J. Geod. 2005, 79, 103-110. [CrossRef]

15. GLONASS ICD, GLONASS Interface Control Document; Russian Institute of Space Device Engineering: Moscow, Russia, 2008.

16. Wang, J.; Rizos, C.; Stewart, M.P.; Leick, A. GPS and GLONASS integration: Modeling and ambiguity resolution issues. GPS Solut. 2001, 5, 55-64. [CrossRef]

17. Wanninger, L. Carrier-phase inter-frequency biases of GLONASS receivers. J. Geod. 2012, 86, 139-148. [CrossRef]

18. Dach, R.; Schaer, S.; Lutz, S.; Bock, H.; Orliac, E.; Prange, L.; Thaller, D.; Mervart, L.; Jäggi, A.; Beutler, G.; et al. Annual Center Reports: Center for Orbit Determination in Europe (CODE). In Technical Report 2011; Meindl, M., Dach, R., Jean, Y., Eds.; International GNSS Service, IGS Central Bureau: Pasadena, CA, USA, 2012; pp. 29-40.

19. Chen, H.; Jiang, W.; Ge, M.; Wickert, J.; Schuh, H. An enhanced strategy for GNSS data processing of massive networks. J. Geod. 2014, 88, 857-867. [CrossRef]

20. Blewitt, G.; Bertiger, W.; Weiss, J.P. Ambizap3 and GPS Carrier Range: A New Data Type with IGS Applications; IGS Workshop: Newcastle, UK, 2010.

21. Zumberge, J.F.; Heflin, M.B.; Jefferson, D.C.; Watkins, M.M.; Webb, F.H. Precise point positioning for the efficient and robust analysis of GPS data from large networks. J. Geophys. Res. 1997, 102, 5005-5017. [CrossRef]

22. Ge, M.; Gendt, G.; Rothacher, M.; Shi, C.; Liu, J. Resolution of GPS carrier-phase ambiguities in Precise Point Positioning (PPP) with daily observations. J. Geod. 2008, 82, 389-399. [CrossRef]

23. Rebischung, P.; Griffiths, J.; Ray, J.; Schmid, R.; Collilieux, X.; Garayt, B. IGS08: The IGS realization of ITRF2008. GPS Solut. 2012, 16, 483-494. [CrossRef]

24. Wu, J.; Wu, S.C.; Hajj, G.A.; Bertiger, W.I.; Lichten, S.M. Effects of antenna orientation on GPS carrier phase. Manuscr. Geod. 1993, 18, 91.

25. Schaer, S. Differential Code Biases (DCB) in GNSS Analysis; IGS Workshop: Miami Beach, FL, USA, 2008. 
26. Melbourne, W.G. The case for ranging in GPS-based geodetic systems. In Proceedings of the First International Symposium on Precise Positioning with the Global Positioning System, Rockville, MD, USA, 15-19 April 1985; pp. 373-386.

27. Wübbena, G. Software developments for geodetic positioning with GPS using TI-4100 code and carrier measurements. In Proceedings of the First International Symposium on Precise Positioning with the Global Positioning System, Rockville, MD, USA, 15-19 April 1985; pp. 403-412.

28. Ge, M.; Gendt, G.; Dick, G.; Zhang, F.; Rothacher, M. A New Data Processing Strategy for Huge GNSS Global Networks. J Geod. 2006, 80, 199-203. [CrossRef]

29. Liu, J.; Ge, M. PANDA software and its preliminary result of positioning and orbit determination. Wuhan Univ. J. Nat. Sci. 2003, 8, 603-609.

30. Shi, C.; Zhao, Q.; Geng, J.; Lou, Y.; Ge, M.; Liu, J. Recent development of PANDA software in GNSS data processing. In Proceedings of the International Conference on Earth Observation Data Processing and Analysis (ICEODPA), Wuhan, China, 28-30 December 2008.

31. Boehm, J.; Niell, A.; Tregoning, P.; Schuh, H. Global Mapping Function (GMF): A new empirical mapping function based on numerical weather model data. Geophys. Res. Lett. 2006, 33, L7304. [CrossRef]

32. Saastamoinen, J. Atmospheric correction for the troposphere and stratosphere in radio ranging of satellites. Geophys. Monogr. Ser. 1972, 15, 274-251.

33. Chen, G.; Herring, T.A. Effects of atmospheric azimuthal asymmetry on the analysis of space geodetic data. J. Geophys. Res. 1997, 102, 20489-20502. [CrossRef]

34. Bizouard, C.; Gambis, D. The Combined Solution C04 for Earth Orientation Parameters Consistent with International Terrestrial Reference Frame 2008. IERS Notice. 2011. Available online: http:/ /hpiers.obspm. $\mathrm{fr}$ /iers/eop/eopc04/C04.guide.pdf (accessed on 20 July 2015).

35. Petit, G.; Luzum, B. IERS Conventions (2010); Verlag des Bundesamts für Kartographie und Geodäsie: Frankfurt am Main, Germany, 2010. (In Germany)

36. Lyard, F.; Lefevre, F.; Letellier, T.; Francis, O. Modelling the global ocean tides: Modern insights from FES2004. Ocean Dyn. 2006, 56, 394-415. [CrossRef]

37. Förste, C.; Schmidt, R.; Stubenvoll, R.; Flechtner, F.; Meyer, U.; König, R.; Neumayer, H.; Biancale, R.; Lemoine, J.; Bruinsma, S.; et al. The GeoForschungsZentrum Potsdam/Groupe de Recherche de Gèodésie Spatiale satellite-only and combined gravity field models: EIGEN-GL04S1 and EIGEN-GL04C. J. Geod. 2008, 82, 331-346. [CrossRef]

38. Springer, T.A.; Beutler, G.; Rothacher, M. A New Solar Radiation Pressure Model for GPS Satellites. GPS Solut. 1999, 2, 50-62. [CrossRef]

39. Kouba, J. A simplified yaw-attitude model for eclipsing GPS satellites. GPS Solut. 2009, 13, 1-12. [CrossRef]

40. Dilssner, F.; Springer, T.; Gienger, G.; Dow, J. The GLONASS-M satellite yaw-attitude model. Adv. Space Res. 2011, 47, 160-171. [CrossRef]

41. Rodriguez-Solano, C.; Hugentobler, U.; Steigenberger, P.; Lutz, S. Impact of Earth radiation pressure on GPS position estimates. J. Geod. 2012, 86, 309-317. [CrossRef]

42. Zhang, B.; Ou, J.; Yuan, Y.; Li, Z. Extraction of line-of-sight ionospheric observables from GPS data using precise point positioning. Sci. China Earth Sci. 2012, 55, 1919-1928. [CrossRef]

43. Zhang, B.; Teunissen, P.G. Characterization of multi-GNSS between-receiver differential code biases using zero and short baselines. Sci. Bull. 2015, 1-10. [CrossRef]

44. Arnold, D.; Meindl, M.; Beutler, G.; Dach, R.; Schaer, S.; Lutz, S.; Prange, L.; Sośnica, K.; Mervart, L.; Jäggi, A. CODE's new solar radiation pressure model for GNSS orbit determination. J. Geod. 2015, 89, 775-791. [CrossRef]

45. Rodriguez-Solano, C.J.; Hugentobler, U.; Steigenberger, P.; Bloßfeld, M.; Fritsche, M. Reducing the draconitic errors in GNSS geodetic products. J. Geod. 2014, 88, 559-574. [CrossRef]

(C) 2015 by the authors; licensee MDPI, Basel, Switzerland. This article is an open access article distributed under the terms and conditions of the Creative Commons by Attribution (CC-BY) license (http:/ / creativecommons.org/licenses/by/4.0/). 